\title{
A model for focussed small-group workshops in mathematics
}

Toby Bailey, George Kinnear, Steven O'Hagan'1, Ruth Reynolds, Reuben Wheeler with input from Isambard Goodbody and Rhania Macbain

\section{Introduction}

This document sets out a model for focussed small-group workshops in mathematics. The purpose of the model is to support students to complete challenging (for-credit) assignments to a high standard. The model consists of a pattern of activities where students work on problems before and after a live session. The preparation is a way to maximise the benefit of live sessions.

This document originated as advice intended to help course organisers within the School of Mathematics at The University of Edinburgh prepare their response to COVID-19. As no single model will suit all courses or all institutions, this document is intended to be helpful and not prescriptive. It is intended to give course organisers ideas and provide a starting point for discussions between colleagues. Some adaptations to the model are suggested in Appendix B.

We begin by describing the standard model that has been used for small-group workshops in the School of Mathematics for several years before going on to describe the focussed model in detail. Due to the pandemic, we assume the model is being implemented entirely online. However, there is no need for the model to be implemented online; we think it would work just as well after a return to on-campus teaching.

\section{Context}

\section{The standard workshop model}

In the standard model, most common in the School of Mathematics, a typical workshop means students sitting in groups of six with one tutor for every two groups (see Figure 1 on the next page). There is one "super-tutor" overseeing the whole class, which might have up to 100 students. In practice, the super-tutor is often only there to start the session off and to respond to questions from tutors.

Workshops under the standard model usually have two purposes. First, they allow tutors to give assessed hand-in work back to students and to discuss feedback. The second, and main purpose, is for the students to work on a set of mathematical tasks with their peers. The tasks will usually be new to the students.

\footnotetext{
1 Steven O'Hagan s.ohagan@ed.ac.uk Learning Designer, School of Mathematics, University of Edinburgh.
} 

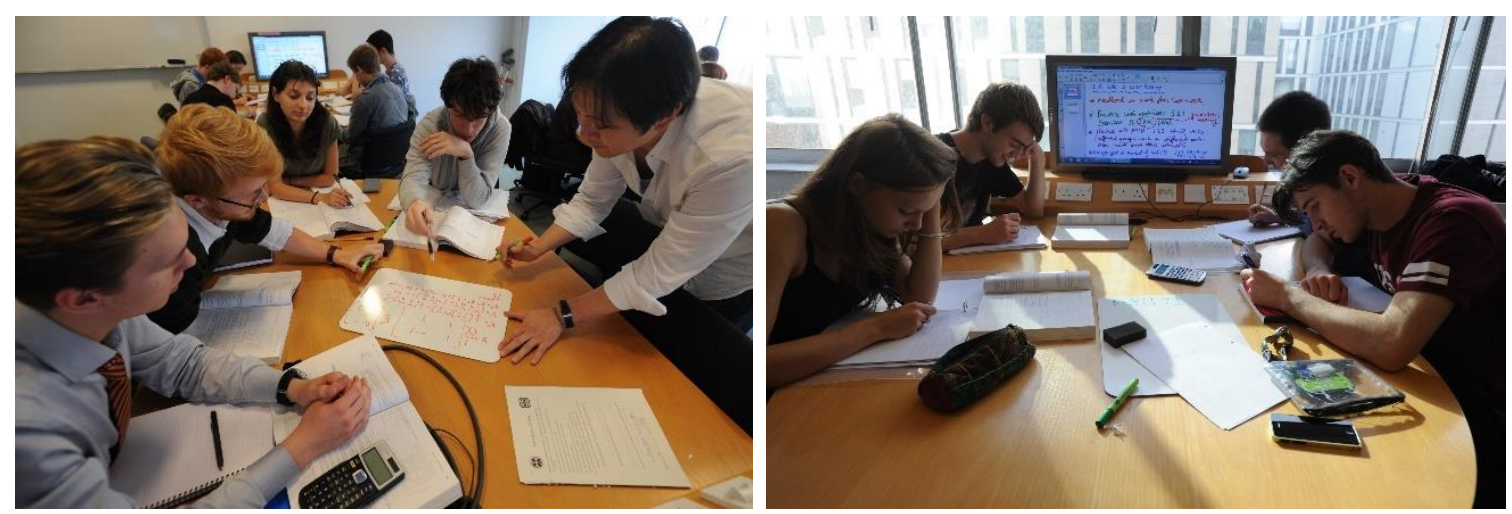

Figure 1: Photographs showing groups of students in a typical workshop?.

The standard model has worked well for many years, though a few issues have been observed.

i. There can be a significant delay between students submitting assessed hand-in work and having it returned with feedback, by which time the task is not fresh in their minds.

ii. Presenting unseen tasks can lead to time being used inefficiently in the workshop as students need to become familiar with the problem. Moreover, students may then progress at different paces leading to difficulties in managing group work.

iii. Some students do not make significant progress with the workshop tasks in the time available and students (even high-attaining ones) admit to rarely completing unfinished work after class.

iv. There is sometimes little interaction between students within a group unless prompted by the tutor.

v. Students' experiences can vary greatly depending on their tutor: some tutors tend to lecture students rather than allow them to work together; some tutors spend a long time returning hand-in work and discussing feedback rather than encouraging students to engage with the intended work. ${ }^{3}$

The design of the focussed model is intended to address these issues.

\section{Assumptions}

The focussed model assumes a level of staff resourcing similar to standard model workshops. Namely, for every $12-15$ students, the tutor has:

- 60 minutes of contact time (weekly for 20 -credit ${ }^{4}$ courses, fortnightly for 10 -credit courses);

- 60 minutes for marking; and

- 30 minutes for preparation.

Note that, in the standard model, the person marking a particular student's assessed hand-in work is usually their tutor. This seems mainly to be a consequence of having to manage paper submissions, though it does also mean that a tutor gets to know a student face-to-face as well as through their written assignments. There is no need to assume that the marker of a student's assessed hand-in work is their tutor if students submit their work digitally.

\footnotetext{
2 Photographs (c) 2014 The University of Edinburgh. All rights reserved.

3 There is, of course, nothing wrong with such variation but it may mean that students are not getting what the course organiser had intended from workshops. In any case, it is worth noting that, in the standard model, the quality of the learning experience depends heavily on tutors. Consequently, the training and management of tutors need to be high priorities, especially when there is a frequent turnover of staff.

${ }^{4}$ By "credits" we mean Scottish Credit and Qualifications Framework credit points (see https://scqf.org.uk/aboutthe-framework/). Students typically take courses worth a total of 60 credits in each semester.
} 


\section{Aims and rationale of the focussed model}

\section{To encourage effective group work} between students.

To nurture a sense of community among students, between students and their tutors, and encourage collaboration away from class. To promote student engagement with
course material.

To give students actionable feedback on their progress.
Students can learn from each other, just as they can from peer instruction in lectures.

With a lot of work happening remotely, reducing isolation, and building a sense of community will be particularly important.

With on-campus contact hours reducing in other course activities, we should incentivise meaningful student engagement.

Feedback is more likely to be effective if students can act on it and have their improvement recognised.

To provide an opportunity for students to seek one-to-one support from tutors.
Students value personal contact with staff, and this is easier to achieve in small groups.

\section{Overview of the focussed model}

Running live sessions online imposes extra constraints, meaning that more structure and routine is needed than for previous on-campus workshops. For instance, during on-campus workshops it was possible for students to have quiet one-to-one conversations ("is this right?"), or for the tutor to move between groups and pick up on subtle cues that students would benefit from some help.

The model replaces an on-campus workshop with a pattern of activities. The model is structured around a challenging assignment, counting for course credit. The purpose of the live activities are designed to support students to tackle the assignment and complete it to a high standard.

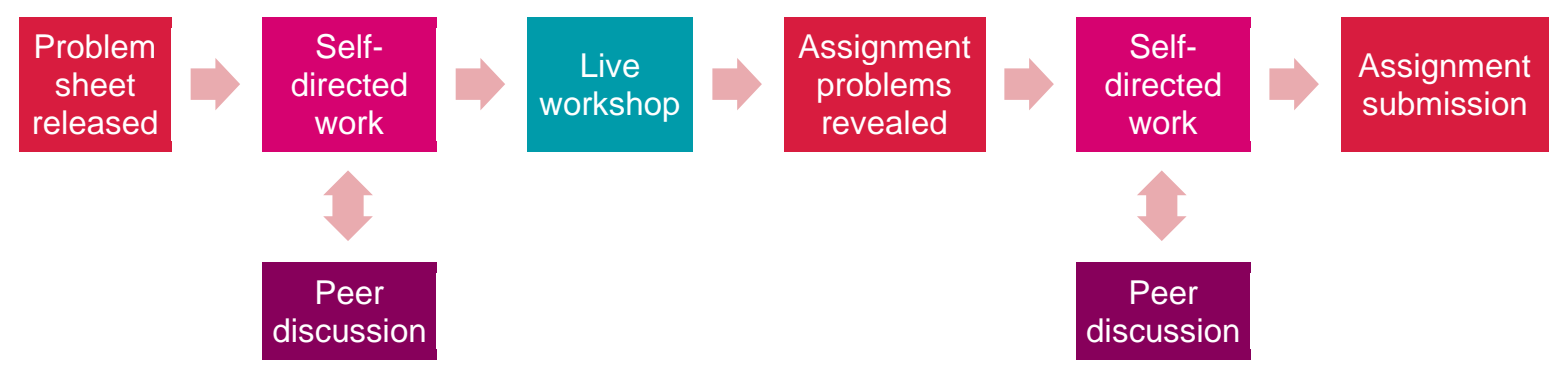

Figure 2: Pattern of activities in the focussed model.

Possible schedules for these activities are shown in Appendix A.

\section{Organisation}

Each student belongs to one workshop group (typically comprising 12-15 students). Each workshop group is made up of a number of smaller subgroups (typically 4-5 students). Each group has one tutor.

$$
\text { ะ }
$$


To provide maximum flexibility, there is no assumption that meetings of several workshop groups happen simultaneously. (There are no super-tutors in this model.) Each workshop group could meet whenever is convenient for its members and its tutor though, in practice, there are likely to be certain timetabled slots for each course.

Our suggested implementation of the model makes use of Blackboard Learn, Piazza, Microsoft Teams, OneNote and Gradescope (see Appendix C for justification of these choices of tools). However, the model can be implemented using other tools - for example, we have seen it work well with Zoom and without OneNote. Whatever tools are used, the above groupings will have to be realised and kept up to date. Some of this synchronisation may happen automatically if tools are interconnected. The intention is that course administrators will be trained to do most of the rest of this administration, with the remainder delegated to tutors.

\section{Details of activities}

Here we explain each step of the model in more detail. See Appendix B for some possible features of and modifications to the model.

\section{Problem sheet released (on Learn)}

The lecturer releases the problem sheet to students. These have around 10 problems with the first 6 being "exercises" which are relatively straightforward and the final 4 being "problems" which are more challenging. Students should be able to complete the exercises with some peer discussion in advance of the workshop and there should be little (if any) discussion of them during the workshop. The 4 problems should be the focus of the workshop and students are aware that 2 of the 4 problems will form the next assignment, due shortly after the live workshop. The knowledge of the coming assignment provides an incentive for meaningful participation, without simply rewarding attendance.

The lecturer also releases solutions and any guidance notes to tutors. The guidance notes might indicate how much help the lecturer wants students to be given with each problem and clearly state "this far and no further" so that tutors do not inadvertently give students too much help with problems that will form their next assignment.

\section{Self-directed work and peer discussion (on Piazza or whatever tools students wish)}

Students start working on the exercises and problems. Meanwhile, in Piazza, students may post questions within their group. There is no expectation that the tutor helps in advance of the workshop - this is an opportunity for peer discussion - but the tutor may use the discussion to help prepare for the workshop. Course organisers may wish to direct tutors to prompt discussion ahead of workshops.

\section{Live workshop (on Teams, 60-minutes)}

The tutor and students join a Teams meeting at the scheduled workshop time.

\section{Starting the workshop - no more than 10 minutes}

- The purpose of this phase is to welcome and settle students and get them organised into their subgroups and ready to work together.

- Depending on the questions raised in advance, the tutor may wish to speak to the group as a whole or give a particular example. This may include some brief discussion of the previous assignment, if there are common issues relevant to the whole group.

- Q\&A calling on individual students, for example to clarify comments on Piazza that might benefit the whole group. 
- After no more than 10 minutes the students should be broken into their subgroups and start discussing the four workshop problems.

\section{Subgroup work - 10-15 minutes per problem as required}

- Students collaborate on written work, using OneNote as needed. The tutor may wish to prepopulate the notebook with copies of the problems to ease collaboration and include the time at which the students should aim to start discussing each problem.

- The tutor visits each subgroup in turn or when called on.

- Students should make some progress, not necessarily finishing the problem as they will still have more time after the workshop to complete the assignment.

- Students stay in their subgroups until the end of the live workshop session.

Each tutor usually has three subgroups (breakout rooms) to manage simultaneously. This has proven to be manageable when the emphasis of the session is on peer discussion and students are expected to articulate their subgroup's difficulties. There is not enough time for the tutor to present complete solutions to each of the three subgroups, which helps to reinforce the studentled design of the model.

The aim of the live workshop is not that students produce a complete solution by the end - there is not enough time for that - it is that each student is confident that they could write up a complete solution to each of the four problems if they had to.

Note that there is no mention of discussing an individual student's feedback on the previous assignment during workshops. This is a choice rather than oversight: the written feedback provided by the marker (who may not even be the tutor) should be sufficient for students to know where they have gone wrong and allow them to try again. In addition, to quote Dylan Wiliam, "feedback should be more work for the recipient than the donor" so, in the case where a student has questions about the written feedback, it should be the student's responsibility to seek clarification.

\section{Self-directed work and peer discussion (on Piazza or whatever tools students wish)}

After the workshop, and now with knowledge of which problems form the next assignment, the students can continue to work with their peers informally. They will have access to various tools and will have built up experience using them - particularly Piazza and Teams. They should also have made sufficient progress in the workshop to have a solid basis for discussing the problems, whether with their subgroup, their group or others in the class.

\section{Assignment submission (on Gradescope)}

Students scan and submit their written work electronically. Work from a particular group can be easily identified and marked by the appropriate person. For example, the course organiser may prefer to the have the assignment marked horizontally (where each marker assigned to a particular question across all scripts) to improve consistency.

\section{Marked work returned to students (on Gradescope)}

Marked work is returned to students at least 24 hours before the next workshop. Additionally, students may be given an opportunity to act on written feedback that they have been given; see Appendix B.1 for one possible way of doing this using assignment resubmission. 


\section{Meeting our aims}

The design choices made attempt to address each of the aims listed previously.

\begin{tabular}{|l|l|}
$\begin{array}{l}\text { To encourage effective } \\
\text { group work between } \\
\text { students. }\end{array}$ & $\begin{array}{l}\text { Forming small, consistent subgroups should reduce student anxiety } \\
\text { when communicating in virtual environments. A structured way of } \\
\text { working, with time for asynchronous preparation, should maximise } \\
\text { the benefit of the synchronous group activity. }\end{array}$ \\
\hline
\end{tabular}

To nurture a sense of community among students, between students and their tutors, and encourage

Working in subgroups of 3-4 that remain consistent for a period of more than one tutorial should facilitate the development of social bonds. Teams channels will be available permanently for chat. Students will become familiar with using these tools for collaboration.

collaboration away

from class.

To promote student engagement with course material.

To give students actionable feedback on their progress.

To provide an opportunity for students to seek oneto-one support from tutors.
Structuring the activities around assessed work should motivate students to engage. They should be more likely to participate in preworkshop peer discussion, to attend and participate meaningfully in workshops, and to participate in post-workshop discussion.

Peer discussion before, during and after the live session, and tutor feedback in the live session, gives students opportunity to obtain feedback and act upon it before the assignment submission deadline.

By giving students time before workshops to think about assignments and discuss problems with their peers, they are encouraged to articulate their difficulties with problems in more sophisticated ways than simply stating "I don't know how to do Problem A".

In designing this model, and the activities within it, care was taken to think about the messages that might be sent to students and any perverse incentives that might be created. All students are individuals, of course, but Appendix D lists some student personas which we used to sense check ideas from different students' perspectives.

\section{Issues to consider}

\section{Admin organisation}

There will need to be a clear plan for who is responsible for each part of the technical setup, and that this workload is both manageable and properly recognised.

\section{Induction and training}

It will be important that tutors and students understand the purpose of the focussed model; namely, to support students to complete challenging assignments to a high standard. The purpose of activities in the pattern in Figure 2 (on page 3 ) should be explained clearly.

Tutors and students should have training in the tools being used.

Because group work is involved, it may be worth considering how to establish good working practices, for example by having an explicit discussion of "how we will work together" (which may be formalised into a group contract). If subgroup assignments are being used (see Appendix B.2) then peer evaluation might be used as part of the assessment. 


\section{Maximising student engagement}

Experience with flipped lectures suggests that if students come to lectures unprepared, the lecturer should not relent and give a traditional lecture: this sends the message that the preparation is not actually required. Similarly, in the focussed workshop model, we need to ensure that students are incentivised to do meaningful preparation for the live session - in particular, by avoiding tutors using the live session simply to present worked solutions.

\section{Appendix A: Possible schedules of activities}

Example: workshop and assignment every fortnight

$\begin{array}{lllll}\text { Mon } & \text { Tue } & \text { Wed } & \text { Thu } & \text { Fri }\end{array}$

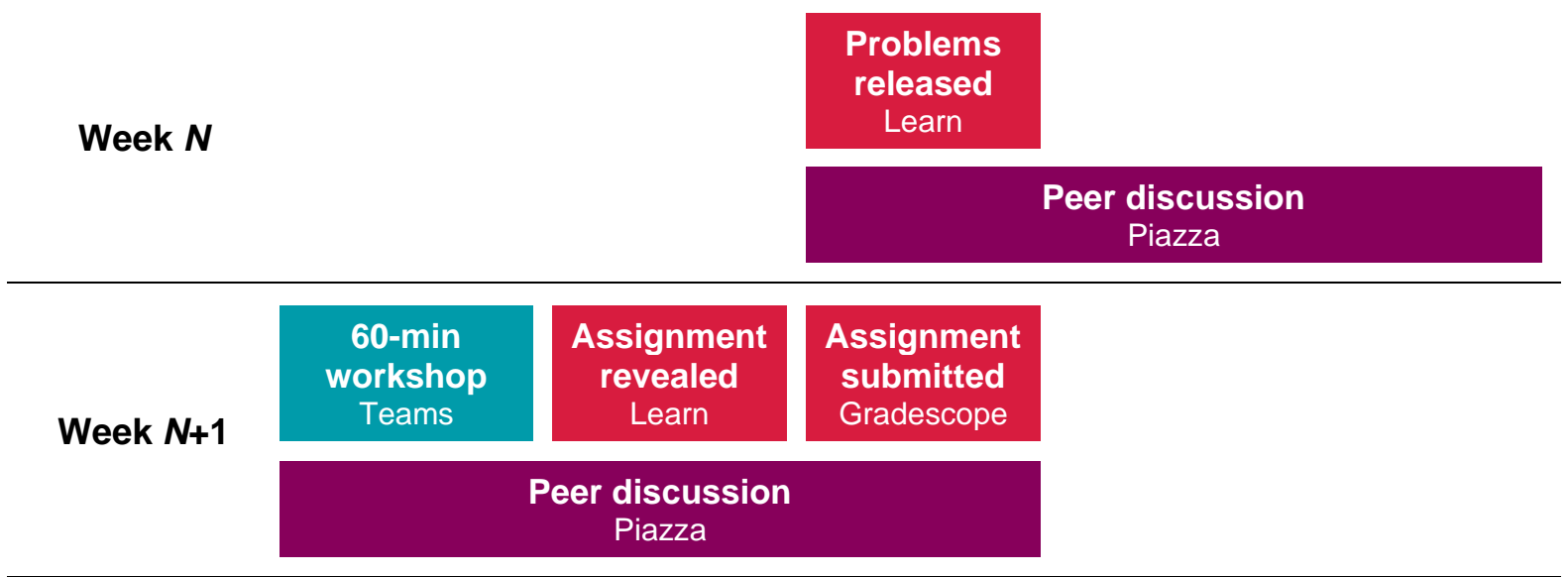

Week $\mathbf{N + 2}$

Marked

work

returned to

students

Gradescope

Example: workshop every week, assignment every fortnight

$\begin{array}{lllll}\text { Mon } & \text { Tue } & \text { Wed } & \text { Thu } & \text { Fri }\end{array}$

\begin{tabular}{|c|c|c|c|c|c|}
\hline & Mon & Tue & Wed & Thu & Fri \\
\hline \multirow{2}{*}{ Week $N$} & & & & $\begin{array}{l}\text { Assignment } \\
\text { released } \\
\text { Learn }\end{array}$ & \\
\hline & & & & Peer di & \\
\hline \multirow{2}{*}{ Week $N+1$} & & $\begin{array}{l}\text { 60-min } \\
\text { workshop } \\
\text { Teams }\end{array}$ & $\begin{array}{l}\text { Assignment } \\
\text { revealed } \\
\text { Learn }\end{array}$ & $\begin{array}{l}\text { Assignment } \\
\text { submitted } \\
\text { Gradescope }\end{array}$ & \\
\hline & \multicolumn{3}{|c|}{$\begin{array}{c}\text { Peer discussion } \\
\text { Piazza }\end{array}$} & & \\
\hline
\end{tabular}

Week $\mathbf{N + 2} \begin{gathered}\text { Marked work } \\ \text { returned to } \\ \text { students } \\ \text { Gradescope }\end{gathered}$ 


\section{Appendix B: Suggested features and modifications}

\section{B.1 Specifications grading of assignments with resubmission}

The model makes no assumptions about the way assignments are marked. However, building on the principle that students should be able to act on the feedback that they are given, you might consider using specifications grading (sometimes also known as mastery-based grading) and allow students to resubmit solutions to certain problems in the future.

One such marking rubric is EMRF, which is described in a blog post by Robert Talbert: https://medium.com/@roberttalbert/specifications-grading-with-the-emrf-rubric-426a5b191a65

There is also a video of Robert describing how he has used the rubric (under a different name) to assess mathematical proofs and giving some ideas about how to communicate the rubric clearly to students: https://youtu.be/wxgGTCFa3IM?t=3065

There are various ways to implement resubmission of problems. For example, only allowing students a certain number of resubmissions during the course or where their first attempt was of a suitable standard (to avoid the handing in of poor attempts). You might want to allow students to gain full credit for resubmissions or only allow them to improve their original grade by within a certain range.

Resubmission can, of course, mean that there is more student work to be marked overall, but using a simple marking rubric like EMRF can reduce the time taken to mark each piece of work.

\section{B.2 Subgroup assignments}

The assignment submission could be at the subgroup level rather than individual. This would reduce the marking workload and could further enhance the subgroup's collaboration.

There are many options here, such as:

- Combining this with the resubmission idea in B.1, e.g. after getting feedback on their individual attempts, students can resubmit a single subgroup attempt that draws on all their work and the feedback received.

- The assignments could be a mixture of individual and subgroup-based, for example four subgroup assignments followed by one individual assignment.

- Having subgroups appoint a scribe whose job it is to write up a particular assignment submission might help the subgroups to work better together.

- Including an element of peer evaluation in the assessment (for example, using a tool like WebPA http://webpaproject.com/) allows students in subgroups to record their perceptions on the respective contributions of team members and have those factored in to mark calculations.

\section{B.3 Initial subgroup-based task}

- In advance of the workshop, each subgroup is assigned a different problem to solve.

- During the workshop, the subgroups take turns presenting their progress, and the other subgroups ask questions of them.

- Need to take care that this is not totally off-putting for students (i.e. they simply disengage to avoid "looking silly" in front of the group) - perhaps by making sure the first assignment has some easily achievable parts, and by making sure tutors handle the initial discussion sensitively, normalising the fact that these are 
challenging problems, and that the point of the workshop is to make progress on them. Possibly also a role here for induction.

- After the workshop, an extension or modification of the assigned problems is made available - each student submits their own individual attempt at these extended problems, drawing on the understanding that they gained from the subgroup work.

\section{Appendix C: Justification for the choice of tools}

\begin{tabular}{|l|l|l|l|}
\hline $\begin{array}{l}\text { Blackboard } \\
\text { Learn }\end{array}$ & $\begin{array}{l}\text { The University's main virtual learning environment. A common source for } \\
\text { students to access information about their courses. }\end{array}$ \\
\hline Piazza & $\begin{array}{l}\text { Will be integrated with Learn in time for the start of Semester } 1 \text { so that all } \\
\text { students will be automatically enrolled in Piazza courses. Students will be } \\
\text { familiar with using it. Groups can be set up in Piazza. }\end{array}$ \\
\hline Microsoft & $\begin{array}{l}\text { All students have accounts in Teams. Setting up groups and subgroups as } \\
\text { channels provides a permanent space for students to leave messages to each } \\
\text { other throughout the course and build a sense of community. Students can also } \\
\text { easily start informal video meetings outside of scheduled classes if they wish. } \\
\text { Why not Zoom? Teams is integrated into other tools, e.g. students' calendars. } \\
\text { It provides a more permanent space that is easily accessible (rather than } \\
\text { relying on links and passwords). Groups can be set up reliably in advance. }\end{array}$ \\
\hline Microsoft & $\begin{array}{l}\text { All students have access to OneNote, which can be used in a web browser or } \\
\text { the standalone Windows or iOS app. Allows for easy distribution of pre- } \\
\text { populated whiteboards to multiple groups of students, which proved more } \\
\text { popular than simply providing a blank shared whiteboard during testing. }\end{array}$ \\
\hline Gradescope & $\begin{array}{l}\text { Will be integrated with Learn in time for the start of Semester } 1 \text { and available } \\
\text { for all courses. Allows for the efficient submission, marking and return of } \\
\text { student work electronically. }\end{array}$ \\
\hline
\end{tabular}

\section{Appendix D: Student personas}

- Student who has fallen behind on the reading or only done some of the relevant reading of the week. Must be prompted to review relevant material or seek assistance from peers despite poor progress.

- Reserved, capable and motivated student. Has made good progress prior to the workshop.

- Reserved, capable and unmotivated student. Assumes many of the workshop questions are simple and must be prompted to attempt those questions.

- Reserved and struggling student. Tutor must carefully ask questions to identify the areas the student finds difficult.

- Capable student who answers questions before other students have had a chance to reflect.

- Confident student who will put forward answers, even if uncertain, if the group seems withdrawn.

- International student who prefers to solve problems paired with a speaker of their native language. Capable of communicating progress with tutor or asking questions of peers when needed. 